\title{
The Information Content of the Exchange Rate and the Stability of Real Output under Alternative Exchange-Rate Regimes
}

\author{
Kent P. Kimbrough* \\ Department of Economics, Duke University, \\ Durbam NC'27706, USA
}

\begin{abstract}
When the exchange rate is flexible, and thus responds to market forces, it provides agents with useful information, while when it is fixed (by a feedback rule) it does not. The implications of this asymmetry for the stability of real output under the two regimes is discussed. It is shown that whenever shocks are predominantly of one variety, or when domestic monetary shocks are accompanied by one real shock, a flexible exchange rate does a better job of stabilizing real output than does a fixed exchange rate. These results undermine arguments favoring fixed exchange rates because they 'discipline' monetary policy. In addition, it is demonstrated that managed floating rules and exchange rate feedback rules are irrelevant for the distribution of real output.
\end{abstract}

One of the important policy questions confronting any country is the choice among alternative exchange-rate regimes. Policymakers must decide whether to allow their currency to float freely, to peg their currency to some other currency (or basket of currencies), or to pursue a managed float. The choice has important implications for the stability of real output and consumption, the rate of inflation and its variability, and many other key economic variables. There is a vast literature in international economics concerning this choice, but the issue of which regime is superior has yet to be, and indeed may never be decided one way or the other. Earlier work on the subject ${ }^{1}$ focused on the choice between fixed and flexible exchange rates, raising such issues as the risk and uncertainty involved in international transactions, the efficacy of monetary and fiscal policy, and the insulation from external shocks under the two systems. More recently, the literature has concentrated on the implications of alternative exchange rate regimes for the stability of real output. Boyer (1978)

* I would like to thank Grant Gardner and George Tauchen for their many helpful comments. The comments of an anonymous referee which greatly improved the paper are also gratefully acknowledged. Between the time this paper was completed and accepted for publication a paper by Chan (1982) addressing similar issues under conditions of sticky wages and prices came to my attention.

0261-5606/83/01/0027-12\$03.00 (C) 1983 Butterworth \& Co (Publishers) Ltd 
uses an open economy IS-LM model to demonstrate that when shocks are real in nature flexible exchange rates are superior to fixed exchange rates on this score, while if shocks are monetary the reverse is true. Cox (1980), Weber (1981), and Flood and Marion (1982) all extend Boyer's model in various directions. ${ }^{2}$

The purpose of this paper is to call attention to one fundamental difference between fixed and flexible exchange-rate regimes that has not yet been brought out in the literature. The difference concerns the information content of the exchange rate under the two regimes. Under a flexible exchange-rate regime, fluctuations in exchange rates reflect movements in the underlying determinants of the supplies of and demands for various currencies. That is, exchange rates reflect market forces, and hence convey information to agents about current economic conditions. However, under a fixed exchange-rate regime, which here means any system whereby exchange rates are determined by some sort of feedback rule, exchange rates do not reflect market forces, and hence do not convey any information at all to agents about current economic conditions. ${ }^{3}$ To put the argument succinctly, exchange rates provide agents with useful information when they are flexible, but their information content is nil when they are fixed (i.e., determined by a feedback rule).

The remainder of the paper is devoted to demonstrating this proposition, and to drawing out its implications for the stability of real output under fixed and flexible exchange rates. In the following section a very simple, ad boc macrueconomic model designed to highlight in a stark fashion the difference between the information content of the exchange rate under these two alternative exchange rate regimes is presented. ${ }^{4}$ Sections II and $\mathrm{III}$ of the paper discuss the determination of equilibrium under the two exchange-rate regimes and derive two policy-ineffectiveness propositions. In Section II it is shown that the distribution of real output is not influenced by any managed floating (money supply) rule adopted by the monetary authorities, while in Section III it is argued that when the exchange rate is fixed the distribution of real output is independent of the type of feedback rule chosen. In Section IV the two regimes are compared on the basis of their implications for the stability of real output. Although it cannot be demonstrated that one regime dominates the other on this scorc, two important conclusions emerge from the discussion.

1. Whenever shocks are predominantly of one kind, flexible exchange rates are superior to fixed exchange rates. This conclusion is independent of the source of the predominant shocks (real or monetary, domestic or foreign).

2. It is also demonstrated that when the economy is affected by domestic monetary shocks and shocks of one other kind, either real or foreign in origin, flexible exchange rates are again superior to fixed exchange rates.

These results have important implications for the conduct of macroeconomic policy in an open economy and are in marked contrast to the results of Boyer (1978), Cox (1980), and Weber (1981). Section V of the paper contains concluding remarks.

\section{The Model}

The model used to derive the aforementioned results is described by the following three equations:

$$
m_{t}=\beta p_{t}+(1-\beta)\left(e_{t}+p_{t}^{*}\right)+\phi y_{t}
$$




$$
\begin{gathered}
y_{t}=\theta\left[p_{t}-E\left(p_{t} \mid I_{t}\right)\right]+u_{t}^{s} \\
y_{t}=\delta\left(e_{t}+p_{t}^{*}-p_{t}\right)+u_{t}^{d}
\end{gathered}
$$

All variables are expressed in logarithms and are deviations from their trend values (where trend values are defined as those values expected by agents on the basis of information available to them at the end of period $t-1$ ). In addition, all of the parameters in equations $\langle 1\rangle-\langle 3\rangle$ are defined to be positive.

Equation $\langle 1\rangle$ is the money market equilibrium condition (or LM curve). The money supply at time $t, m_{\text {, }}$, must equal the demand for money which depends on real output, $y_{t}$, and the domestic price level. The latter is a weighted average of the price of domestic output, $p_{t}$, and the domestic currency price of foreign output which depends on its foreign currency price, $p_{t}^{*}$ (mean zero and variance $\sigma_{p^{*}}^{2}$ ), and the exchange rate, $e_{t}$ (domestic currency price of foreign exchange). The weights are given by the share of each good in domestic expenditure.

The aggregate supply function is given by equation $\langle 2\rangle$, where $E\left(p_{t} \mid I_{t}\right)$ is the price of domestic output agents expected to prevail during period $t$ conditional on the information available to them, $I_{t}$. This information set includes not only all information available at the end of period $t-1$, but also includes the current exchange rate. The rationale for this is that the exchange rate is an asset price and is determined in a well organized market and information about it is thus more readily accessible (i.e., less costly to obtain) than is information on the prices of domestic and foreign goods. Agents' expectations are assumed to be formed rationally. The term $u_{t}^{s}$ in equation $\langle 2\rangle$ reflects random elements that influence real output; it has mean zero and variance $\sigma_{w s^{*}}^{2}$

Equation $\langle 3\rangle$ is the aggregate demand for domestic output (or IS curve). ${ }^{5} \mathrm{~A}$ fall in the relative price of domestic output (i.e., a rise in $e_{t}+p_{t}^{*}-p_{t}$ ) increases the demand for domestic output. This is captured by the first term in $\langle 3\rangle$. In addition, random elements, reflected by $u_{t}^{d}$ (zero mean, variance $\sigma_{u d}^{2}$ ), also affect the demand for domestic output.

Before proceeding, two observations about the model are in order.

1. The country in question is assumed to be large in its export market and small in its import market. Hence the price of domestic output, $p_{t}$, is endogenous, while the price of foreign output, $p_{t}^{*}$, is taken to be exogenous. However, it should be stressed that the qualitative results discussed in Section IV do not depend on this assumption-other models will lead to similar conclusions. ${ }^{6}$

2. There is no interest rate in the model. The reason is that it has been assumed that the interest rate elasticities of the money demand and aggregate demand functions are zero. This assumption simplifies the solution of the model presented in Sections II and III, but relaxing it would not alter the conclusions presented in Section IV as long as the home country is taken to be small in the world asset market. ${ }^{\text {I }}$

\section{Equilibrium with a Flexible Exchange Rate}

As pointed out in the introduction, when the exchange rate is flexible it reflects market forces and thus conveys information to agents about the current state of the economy. The problem confronting agents is how to best use this information in forming their expectations about the price of domestic output, $E\left(p_{t} \mid I_{t}\right)$. Once this 
problem is solved, and a solution for $E\left(p_{t} \mid I_{t}\right)$ has been found, equations $\langle 1\rangle-\langle 3\rangle$ can be used to determine the equilibrium values of real output, domestic goods prices, and the exchange rate. The domestic money supply, $m_{t}$, is determined by the monetary authorities since the exchange rate is flexible, and is one of the model's exogenous variables along with the price of foreign output and the aggregate supply and demand shocks $\left(u_{t}^{s}\right.$ and $\left.u_{t}^{d}\right)$.

Equating $\langle 2\rangle$ and $\langle 3\rangle$ as required for goods market equilibrium, it can be seen that the price of domestic output and the exchange rate must satisfy

$$
(\delta+\theta) p_{t}-\delta e_{t}=\delta p_{t}^{*}+\theta E\left(p_{t} \mid I_{t}\right)+u_{t}^{d}-u_{t}^{s}
$$

In addition, since the equilibrium level of real output is given by $\langle 2\rangle$, it follows from $\langle 1\rangle$ that equilibrium in the money market requires that

$$
(\beta+\phi \theta) p_{t}+(1-\beta) e_{t}=m_{t}-(1-\beta) p_{t}^{*}+\phi \theta E\left(p_{t} \mid I_{t}\right)-\phi u_{t}^{s}
$$

Solving the preceding two expressions for the price of domestic output and the exchange rate yields

$$
\begin{gathered}
p_{t}=a_{1} m_{t}+a_{2}\left[\theta E\left(p_{t} \mid I_{t}\right)-u_{t}^{s}\right]+a_{3} u_{t}^{d} \\
e_{t}=-p_{t}^{*}+b_{1} m_{t}+b_{2}\left[\theta E\left(p_{t} \mid I_{t}\right)-u_{t}^{s}\right]+b_{3} u_{t}^{d}
\end{gathered}
$$

where $^{8}$

$$
\begin{array}{ll}
a_{1}=\frac{\delta}{\Delta}, & b_{1}=\frac{\delta+\theta}{\Delta} \\
a_{2}=\frac{1-\beta+\phi \delta}{\Delta}, & b_{2}=\frac{\phi \delta-\beta}{\Delta} \\
a_{3}=\frac{1-\beta}{\Delta}, & b_{3}=\frac{-(\beta+\phi \theta)}{\Delta}
\end{array}
$$

and $\Delta=\delta+\theta(1-\beta+\phi \delta)>0$. It should also be noted that $a_{1}+\theta a_{2}=b_{1}+\theta b_{2}=1$. This implies that any fully perceived increase in the domestic money supply will be neutral.

As can be seen from $\langle 5\rangle$, under a flexible exchange-rate regime the exchange rate depends on the price of foreign output, the domestic money supply, and aggregate supply and demiand conditions $\left(u_{t}^{s}\right.$ and $u_{t}^{d}$ ); that is, it reflects market forces. Since agents observe the current exchange rate, they will use the information it conveys in forming their expectations. It can be shown that under the assumption of rational expectations ${ }^{9}$

$$
E\left(p_{t} \mid I_{t}\right)=\gamma e_{t} ; \gamma=\sigma_{p e} / \sigma^{2}
$$

where $\sigma_{e}^{2}$ is the variance of the exchange rate and $\sigma_{p e}$ is the covariance between the price of domestic output and the exchange rate. An explicit solution for $\gamma$ is presented shortly.

Using $\langle 6\rangle$ in $\langle 5\rangle$ it can be seen that

$$
e_{t}=\frac{1}{1-b_{2} \theta \gamma}\left(-p_{t}^{*}+b_{1} m_{t}-b_{2} u_{t}^{s}+b_{3} u_{t}^{d}\right)
$$


and using $\langle 6\rangle$ and then $\langle 7\rangle$ in $\langle 4\rangle$ it can be seen that

$$
p_{i}=\left(a_{1}+\frac{a_{2} \theta \gamma b_{1}}{1-b_{2} \theta \gamma}\right) m_{t}-\frac{a_{2}}{1-b_{2} \theta \gamma} u_{t}^{s}+\left[\frac{a_{3}+\theta \gamma\left(a_{2} b_{3}-a_{3} b_{2}\right)}{1-b_{2} \theta \gamma}\right] u_{t}^{d}-\frac{a_{2} \theta \gamma}{1-b_{2} \theta \gamma} p_{t}^{*}
$$

Expressions $\langle 7\rangle$ and $\langle 8\rangle$ are the solutions for the equilibrium exchange rate and the equilibrium price of domestic output under a regime of flexible exchange rates.

These solutions can be used to calculate $\sigma_{e}^{2}$ and $\sigma_{p e}$, from which it can be demonstrated that ${ }^{10}$

$$
\gamma=\frac{a_{1} b_{1} \sigma_{m}^{2}+a_{2} b_{2} \sigma_{w s}^{2}+a_{3} b_{3} \sigma_{w d}^{2}}{a_{1} b_{1} \sigma_{m}^{2}+b_{2}^{2} \sigma_{w s}^{2}-\left(b_{3} \beta / \Delta\right) \sigma_{w d}^{2}+a_{1} \sigma_{p^{*}}^{2}}
$$

It should be noted that the responsiveness of domestic price expectations to changes in the exchange rate depends on the magnitude and type of shocks to which the economy is subject. Changes in the magnitude or type of shocks to which the economy is subject will alter the way in which agents form their expectations (i.e., change $\gamma$ ), and this must be taken into account when attempting to assess the effects of various policy changes. This is the point raised by Lucas (1976) in his critique of econometric policy evaluation.

From $\langle 4\rangle,\langle 6\rangle,\langle 7\rangle$, and the fact that $a_{1}+\theta a_{2}=1$ it can, with some manipulation, be shown that the domestic price forecast error is

$$
p_{t}-E\left(p_{t} \mid I_{t}\right)=\frac{1}{1-b_{2} \theta \gamma}\left[a_{1}(1-\gamma) m_{t}-\left(a_{2}-b_{2} \gamma\right) u_{t}^{s}+\left(a_{3}+\frac{\gamma \beta}{\Delta}\right) u_{t}^{d}+a_{1} \gamma p_{t}^{*}\right]
$$

Using this in $\langle 2\rangle$, and rearranging the coefficient of $u_{t}^{d}$ a bit, it follows that

$$
y_{t}=\frac{\theta a_{1}}{1-b_{2} \theta \gamma}\left[(1-\gamma) m_{t}-\frac{a_{2}-b_{2} \gamma}{a_{1}} u_{t}^{s}+\frac{1-\beta(1-\gamma)}{\delta} u_{t}^{d}+\gamma p_{t}^{*}\right]+u_{t}^{s}
$$

One interesting implication of $\langle 10\rangle$ is that the adoption of a flexible exchange rate does not insulate real output from foreign price shocks. The reason for this is that agents typically lack full current information. ${ }^{11}$ It can, however, be concluded that the more important are foreign shocks (i.e., the smaller $\sigma_{j}^{2} / \sigma_{p^{*}}^{2}$, for all $j$ ), the 'better' job flexible exchange rates do of insulating the domestic economy. This can be seen from $\langle 10\rangle$ by noting that the larger are foreign price shocks, the smaller is $\gamma$ (in absolute value), and hence the less influence foreign price shocks exert on domestic real output (and prices).

Another implication of $\langle 10\rangle$ is that the information content of the exchange rate, as reflected by $\gamma$, is crucial for determining how various shocks influence real ourput. For example, it can be seen from $\langle 10\rangle$ that an unanticipated increase in the domestic money supply will increase real output only if $1-\gamma>0 .{ }^{12}$ If $1-\gamma<0$ an unanticipated increase in the domestic money supply will actually reduce real output. ${ }^{13}$ Notice from $\langle 7\rangle$, however, that the information content of the exchange rate plays no role in determining the qualitative effects of the various shocks on the exchange rate (although it does influence their quantitative effect). As can be seen from $\langle 7\rangle$, positive foreign price shocks and aggregate demand shocks will be accompanied by an appreciation of the exchange rate, an increase in the domestic money supply will lead to a depreciation, and a positive aggregate supply shock may work in either direction. ${ }^{14}$

One final implication of the model concerns the issue of managed floating. In the 
present framework managed floating can be represented by a money supply rule of the form

$$
m_{t}=k e_{t}+\eta_{t}
$$

where $\eta_{t}$ has mean zero (conditioned on $I_{t}$ ) and variance $\sigma_{\eta}^{2}$, and $k$ is a policy parameter selected by the monetary authorities. Up to this point it has implicitly been assumed that $k=0$ implying a 'clean' float. An implication of the model that should be stressed is that one managed exchange rate rule (value of $k$ ) is as good as any other from the standpoint of stabilizing real output. ${ }^{15}$ This result is an open economy extension of the policy-ineffectiveness proposition advanced by Sargent and Wallace (1975). It follows from the fact that since agents know the current exchange rate, any policy conditioned on the current exchange rate will fail to affect agents' forecast errors, $p_{t}-E\left(p_{t} \mid I_{t}\right)$, and thus will be irrelevant for the distribution of real output. ${ }^{16}$

\section{Equilibrium with a Fixed Exchange Rate}

The term fixed exchange rate is used here to apply to any regime under which the exchange rate is determined by some sort of feedback rule. Since policymakers have access to the same information as private agents the exchange rate feedback rule can be written as ${ }^{17}$

$$
e_{t}=g \cdot \Omega_{t-1}
$$

where $g$ is a vector of parameters that is conformable to $\Omega_{t-1}$.

In the introduction it was claimed that a fundamental difference between fixed and flexible exchange rates is that when the exchange rate is fixed by a feedback rule and does not respond to market forces its information content is nil. This is apparent from $\langle 11\rangle$. Since the exchange rate depends only on $\Omega_{t-1}$, and since agents already have this information (which includes knowledge of $\langle 11\rangle$ ), observing the exchange rate does not provide agents with any additional information they can use in forming their expectations. Hence $E\left(p_{t} \mid I_{t}\right)=E\left(p_{t} \mid \Omega_{t-1}\right)$ under a fixed exchange rate regime.

Therefore, equations $\langle 1\rangle-\langle 3\rangle$, in conjunction with $\langle 11\rangle$, determine the equilibrium values of real output, domestic prices and the domestic money supply. As is well known, the domestic money supply is an endogenous variable when the exchange rate is fixed because in order to support a feedback rule like $\langle 11\rangle$ the monetary authorities are committed to buy and sell foreign exchange; the domestic money supply thus adjusts via the balance of payments to maintain money market equilibrium.

Setting $\langle 2\rangle$ and $\langle 3\rangle$ equal, as required for goods market equilibrium, using $\langle 11\rangle$, and solving for $p_{r}$ yields ${ }^{18}$

$$
p_{t}=\frac{1}{\delta+\theta}\left(\delta p_{t}^{*}+u_{t}^{d}-u_{t}^{s}\right)
$$

Using $\langle 12\rangle$ in $\langle 2\rangle$ it follows that

$$
y_{t}=\frac{1}{\delta+\theta}\left(\delta u_{t}^{s}+\theta u_{t}^{d}+\theta \delta p_{s}^{*}\right)
$$


Substituting $\langle 12\rangle$ and $\langle 13\rangle$ into $\langle 1\rangle$ it can be seen that the domestic money supply is given by

$$
m_{t}=\frac{1}{\delta+\theta}\left[(\phi \delta-\beta) u_{t}^{s}+(\beta+\phi \theta) u_{t}^{d}+\Delta p_{t}^{*}\right]
$$

Equations $\langle 12\rangle-\langle 14\rangle$ are the solutions to the model when the exchange rate is fixed. As can be seen from $\langle 12\rangle$, positive aggregate supply and demand shocks, as well as positive foreign price shocks, all increase the price of domestic output and, as shown by $\langle 13\rangle$ result in an increase in real output. Note also that $m_{\text {, }}$ can be interpreted as the balance of payments (relative to trend) at time $t$. Expression (14) therefore implies that increases in aggregate demand and foreign output prices will improve the balance of payments, while increases in aggregate supply may lead to an improvement or deterioration of the balance of payments as $\phi \delta \gtrless \beta$.

One important point to note from $\langle 13\rangle$ is that none of the parameters of the feedback rule $\langle 11\rangle$ influence the level of real output or its distribution. Therefore, from the standpoint of stabilizing real output one fixed exchange rate rule is as good as any other. This is another open economy cxtension of the policy-ineffectiveness results derived by Sargent and Wallace (1975).

\section{Comparison of Fixed and Flexible Exchange Rates}

In this section fixed and flexible exchange-rate regimes are compared in terms of their implications for the stability of real output. In order to facilitate comparison, the results of Sections II and III are used to calculate the variance of real output about its full current information value, which from $\langle 2\rangle$ is simply $\boldsymbol{u}_{\text {t }}^{s}$. From $\langle 13\rangle$ it can be shown that the variance of real output about its full current information value under a fixed exchange rate, $\sigma_{F i x}^{2}$, is given by

$$
\sigma_{\text {Fix }}^{2}=\left(\frac{\theta}{\delta+\theta}\right)^{2}\left(\sigma_{w d}^{2}+\sigma_{w}^{2}+\delta^{2} \sigma_{p^{*}}^{2}\right)
$$

while from $\langle 10\rangle$ it can be seen that the variance of real output about its full current information value under a flexible exchange rate, $\sigma_{F l e x}^{2}$, is given by

$$
\sigma_{\text {Flex }}^{2}=\left(\frac{\theta a_{1}}{1-b_{2} \theta \gamma}\right)^{2}\left[(1-\gamma)^{2} \sigma_{m}^{2}+\left(\frac{1-\beta(1-\gamma)}{\delta}\right)^{2} \sigma_{w d}^{2}+\gamma^{2} \sigma_{p^{*}}^{2}\right]+\left[\frac{\theta\left(b_{2} \gamma-a_{2}\right)}{1-b_{2} \theta \gamma}\right]^{2} \sigma_{w s}^{2}
$$

The first major point to be demonstrated using $\langle 15\rangle$ and $\langle 16\rangle$ is that when one type of shock is predominant, in the sense that the ratio of the variance of any other shock to its variance is close to zero, a flexible exchange-rate regime is superior to a fixed exchange-rate regime regardless of the source of the predominant shocks. ${ }^{19}$ This can be seen from $\langle 15\rangle$ and $\langle 16\rangle$ by noting that $\sigma_{\text {Flex }}^{2}=0$ in this case while $\sigma_{\text {Fix }}^{2}>0 . .^{20}$ The reason for this result is straightforward. When there is only one important source of noise in the economy, observation of the current exchange rate perfectly reveals the state of the economy to agents, and is thus equivalent to full current information. This result is in contrast to those of Boyer (1978), Cox (1980), and Weber (1981) who argue that when shocks of one type are predominant which exchange-rate regime is superior depends on the source of those shocks and the 
magnitudes of various parameters. The reason for the difference in results lies solely in the fact that the present analysis allows for a difference in the information content of the exchange rate under alternative regimes.

The second major point concerns the case where the economy is affected by domestic monetary shocks along with shocks to either aggregate demand, aggregate supply, or foreign prices. It can be shown that in any of these cases a flexible exchange-rate regime is superior to a fixed exchange-rate regime. The proof is similar in all three cases so, without loss of generality, consider the case where the only shocks influencing the economy are due to fluctuations in the money supply and aggregate demand (i.e., where $\sigma_{p^{*}}^{2}=\sigma_{* v}^{2}=0$ ). It can be seen immediately from $\langle 15\rangle$ that

$$
\frac{\partial \sigma_{F i x}^{2}}{\partial \sigma_{w d}^{2}}=\left(\frac{\theta}{\delta+\theta}\right)^{2}
$$

in this case, while after tedious but straightforward manipulation of $\langle 16\rangle$ it can be shown that ${ }^{21}$

$$
\frac{\partial \sigma_{F l x x}^{2}}{\partial \sigma_{w d}^{2}}=\left(\frac{\theta}{\delta+\theta+\Lambda\left(\sigma_{w d}^{2} / \sigma_{m}^{2}\right)}\right)^{2}
$$

where $\Lambda=(\beta+\phi \theta)^{2} /(\delta+\theta)>0$. From these expressions it is apparent that $\partial \sigma_{l i k x}^{2} / \partial \sigma_{w d}^{2} \leq \partial \sigma_{F i x}^{2} / \partial \sigma_{u d}^{2}$ (with equality when $\sigma_{* d}^{2} / \sigma_{m}^{2}=0$ ). Coupled with the fact that real output is always at its full current information value when only money supply shocks are present, this implies the relation between the variability of real output under fixed and flexible exchange rates shown in Figure $1 .{ }^{22}$ From the figure it can easily be seen that when the only shocks are to the money supply and aggregate demand, a flexible exchange-rate regime is superior to a fixed exchange-rate regime in terms of stabilizing real output. This result carries over to the cases where only domestic monetary shocks and aggregate supply shocks or foreign price shocks are present. Like that for the predominant shock case, this result is in contrast to those

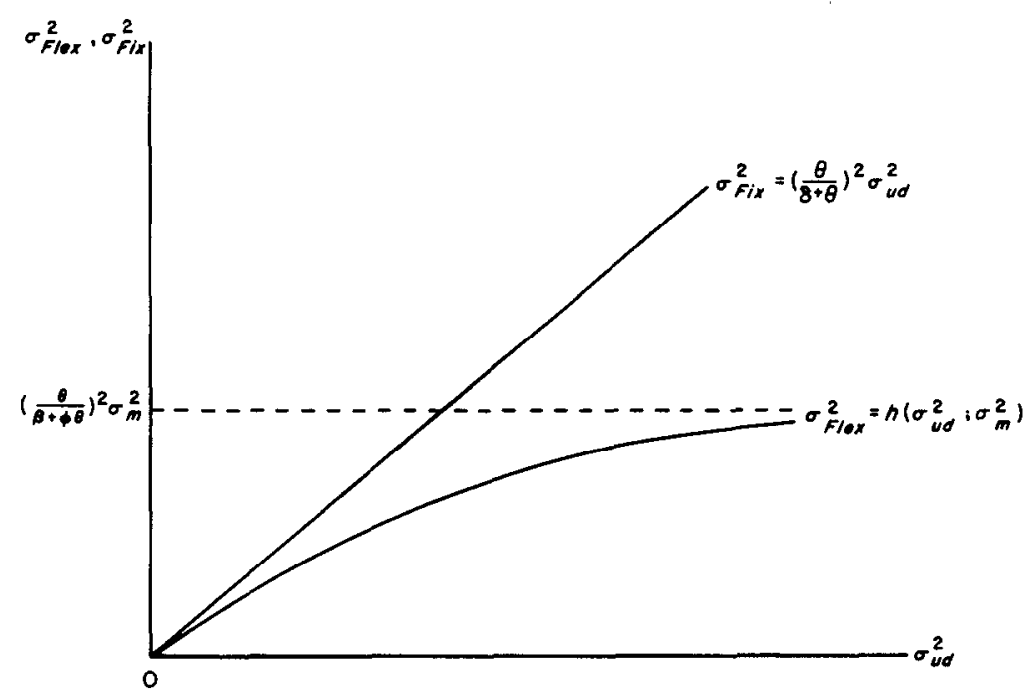

Figure 1. The case where $\sigma_{p^{*}}=\sigma_{w s}^{2}=0$; the function $b(\cdot)$ is given by $\langle 16\rangle$. 
of Boyer (1978) and others. Boyer demonstrates that when shocks are purely monetary in nature a fixed exchange-rate regime results in a more stable level of real output, while when shocks are purely real in nature a flexible exchange-rate regime is superior on this count. In the present framework the two regimes are equivalent when the only shocks are due to money supply fluctuations - under fixed exchange rates real output is insulated from domestic monetary policy while under flexible exchange rates observation of the exchange rate amounts to full current information thus emasculating monetary policy. However, once real shocks, either to aggregate demand, aggregate supply, or foreign prices, enter the picture, the tendency noted by Boyer (1978) for a flexible exchange rate to insulate real output from real shocks takes over, and a regime of flexible exchange rates becomes unambiguously superior in terms of stabilizing real output. ${ }^{23}$

A related point which should be stressed is that the superiority of a flexible exchange-rate regime in these cases would disappear if agents observed the domestic money supply without any lag under a fixed exchange-rate regime. However, there are reasons to believe that this is not a realistic assumption, and to believe instead that agents observe the domestic money supply only with a lag. The exchange rate is a price which is determined in a well-organized asset market and is observable (virtually) free of charge. This is not the case with the domestic money supply. It is not reported as frequently as the exchange rate, and when it is it subject to recording error and seasonal adjustment, both of which make extracting information from it costly. In addition, observing the domestic money supply when the exchange rate is fixed amounts to observing the balance of payments or the foreign exchange operations of the monetary authorities. Since the monetary authorities in most countries take pains to conceal their foreign exchange market transactions, presumably to prevent panics and runs on the currency, it seems unreasonable to assume that money supply information is as readily accessible as exchange-rate information. Therefore, the information asymmetry between fixed and flexible exchange-rate regimes that is assumed here, and that is at the heart of the comparison between them, is a fairly accurate, though stylized, description of the way many economies actually work.

\section{Conclusion}

This paper began by pointing out that there is a fundamental difference between fixed and flexible exchange-rate regimes regarding the information content of the exchange rate. When the exchange rate is flexible it reflects market forces and conveys useful information to agents about the state of the economy, while'when the exchange rate is fixed it does not reflect market forces and its information content is nil. On the basis of this asymmetry, it was shown that when shocks are predominantly of one type, or when domestic monetary shocks are accompanied by one real shock, flexible exchange rates are superior to fixed exchange rates in terms of stabilizing real output. These results cast doubt on arguments favoring fixed exchange rates because they 'discipline' monetary policy; for even if flexible exchange rates are accompanied by an undisciplined monetary policy (i.e., a large $\sigma_{m}^{2}$ ) they will be superior to fixed exchange rates so long as real shocks are primarily of one kind. ${ }^{24}$ The reason for this is that fixing the exchange rate destroys its information content and, when real shocks are primarily of one type, this cost is not made up for by the gains from disciplining monetary policy. In addition, two 
policy-ineffectiveness results were derived. It was shown that one managed floating rule is as good as any other, and that any feedback rule for the exchange rate is as good as any other from the standpoint of stabilizing real output. ${ }^{25}$

Although no definitive proof was offered, there is a strong suggestion that flexible exchange rates are likely to be superior to fixed exchange rates. It would be interesting to test this proposition by doing a cross-country study along the lines of Lucas (1973), or a within-country, across-regimes study to see what the actual experience of countries under the two regimes has been.

\section{Appendix}

Using the definition of $\gamma$ given in $\langle 9\rangle$, and noting that the denominator of this expression is positive, it follows that $1-b_{2} \theta \gamma>0$ implies that

$$
a_{1}\left(b_{1}^{2} \sigma_{m}^{2}+b_{2}^{2} \sigma_{w s}^{2}+\sigma_{p^{*}}^{2}\right)-b_{3}\left(\frac{\beta}{\Delta}+a_{3} b_{2} \theta\right) \sigma_{w d}^{2}>0
$$

All of the terms on the left hand side of $\langle A 1\rangle$ are clearly positive except for that multiplying $\sigma_{u u^{\prime}}^{2}$ However, using the definitions of $a_{3}, b_{2}$, and $\Delta$ it can be shown that

$$
\frac{\beta}{\Delta}+a_{3} b_{2} \theta=-a_{1} b_{3}
$$

Using this in $\langle A 1\rangle$ it can be seen that $1-b_{2} \theta \gamma>0$ implies that

$$
b_{1}^{2} \sigma_{m}^{2}+b_{2}^{2} \sigma_{k s}^{2}+b_{3}^{2} \sigma_{u d}^{2}+\sigma_{p^{*}}^{2}>0
$$

which is always true. Hence $1-b_{2} \theta \gamma>0$ must hold.

\section{Notes}

1. See, for example, the seminal contribution of Friedman (1953).

2. This statement does not do full justice to the richness and variety of these papers, but they are sufficiently different in focus so as to preclude any more specific generalizations without going too far astray of the main argument. One element they all have in common is the addition of a Lucas type aggregate supply function to Boyer's basic framework.

3. This, of course, assumes that the monetary authorities do not have superior information.

4. The model is $a d$ boc in the same sense that the model employed by Sargent and Wallace (1975) is ad boc.

5. The aggregate demand function reflects the demand for domestic output on the part of both domestic and foreign residents.

6. For example, a model in which the home country is taken to be small in all markets will yield similar conclusions.

7. To see why, assume for a moment that interest rate terms were added to equations $\langle 1\rangle$ and $\langle 3\rangle$, and that a fourth equation, an interest rate parity condition, were added to the model. If this were done, it would also seem reasonable to include the domestic and foreign interest rates in the information set for the same reasons that the current exchange rate is included. However, as long as the home country is small in the world asset market, observing the foreign interest rate conveys no information about domestic economic conditions. In conjunction with the interest rate parity condition this implies that observing the domestic interest rate conveys no information about domestic economic conditions that is not already included in the current exchange rate. It should be pointed out, however, that observing the foreign interest rate will convey information about foreign prices since the two are likely to be correlated. Hence the foreign price term, $p_{f}^{*}$, is most appropriately thought of as that component of foreign prices that cannot be predicted on the basis of past information and observation of the current foreign interest rate.

8. In deriving some of the results in this section it is useful to note that $b_{1}=a_{1}+(\theta / \Delta), b_{2}=a_{2}-(1 / \Delta)$, and $b_{3}=a_{3}-(1+\phi \theta / \Delta)$. 
9. This can be seen by noting that agents form $E\left(p_{t} \mid I_{t}\right)$ by regressing domestic output prices on the exchange rate and information available at the end of period $t-1$. The form of $\langle 6\rangle$ follows from the fact that all variables are written as deviations from trend.

10. It can be seen from $\langle 7\rangle$ and $\langle 8\rangle$ that

and

$$
\sigma_{.}^{2}=\frac{1}{\left(1-b_{2} \theta \gamma\right)^{2}}\left(\sigma_{p^{*}}^{2}+b_{1}^{2} \sigma_{m}^{2}+b_{2}^{2} \sigma_{* s}^{2}+b_{3}^{2} \sigma_{m}^{2}\right)
$$

$$
\sigma_{p}=\frac{b_{1}}{1-b_{2} \theta \gamma}\left(a_{1}+\frac{a_{2} \theta \gamma b_{1}}{1-b_{2} \theta \gamma}\right) \sigma_{\omega}^{2}+\frac{a_{2} b_{2}}{\left(1-b_{2} \theta \gamma\right)^{2}} \sigma_{\alpha s}^{2}+\left[\frac{a_{3} b_{3}+b_{3} \theta \gamma\left(a_{2} b_{3}-a_{3} b_{2}\right)}{\left(1-b_{2} \theta \gamma\right)^{2}}\right] \sigma_{\mu d}^{2}+\frac{a_{2} \theta \gamma}{\left(1-b_{2} \theta \gamma\right)^{2}} \sigma_{p^{*}}^{2}
$$

Expression $\langle 9\rangle$ can then be obtained using these results and the definitions of the $a$ 's and $b$ 's in the definition of $\gamma$ given in (6).

11. This point has been stressed by Saidi (1980).

12. It is demonstrated in the appendix that $1-b_{2} \theta \gamma>0$.

13. Using the definition of $\gamma$ it can be shown that this is possible only if $\phi \delta-\beta>0$ and if aggregate supply shocks are 'sufficiently' variable. The possibility that an unanticipated monetary expansion might reduce real output is not new. See, for example, Barro (1976).

14. The reason for this is that a positive aggregate supply shock sets in motion two opposing forces. On the one hand it tends to increase real output, thus leading to an increase in the demand for money and an appreciation. On the other hand it tends to reduce the price of domestic output, thus leading to $a$ decrease in the demand for money and a depreciation. It can be seen from $\langle 7\rangle$ that a positive aggregate supply shock will lead to an appreciation or a depreciation of the exchange rate as $\phi \delta-\beta \gtrless 0$. The first term captures the first effect mentioned above while the second term captures the second.

15. Canzoneri, Henderson, and Rogoff (1981) discuss a similar proposition regarding the nominal interest rate in a closed economy context.

16. Besides being of interest in its own right, this implies that there is no loss of generality in Section IV where a clean float is compared to a fixed exchange-rate regime.

17. To see this let $e_{t}=f_{1} e_{t}+f_{2} \cdot \Omega_{t-1}$. Then by rearranging $e_{t}=\left(f_{2} / 1-f_{1}\right) \cdot \Omega_{t-1}$. Hence $g=\left(f_{2} / 1-f_{1}\right)$. This type of ruie encompasses both adjustable and crawling peg systems such as those that have been used in Brazil, Chile, Israel, and elsewhere.

18. This result follows from $\langle 2\rangle,\langle 3\rangle$, and $\langle 11\rangle$ if one realizes that the notation was abused somewhat in the preceding part of this section. Since all variables are defined as deviations from trend (i.e. their expected value based on $\Omega_{t-1}$ ), it follows that $e_{t}=g \cdot \Omega_{t-1} \equiv 0$ and $E\left(p_{t} \mid I_{t}\right)=E\left(p_{t} \mid \Omega_{t-1}\right) \equiv 0$ under a fixed exchange rate.

19. If the shocks are due to domestic monetary policy the two regimes are equivalent.

20. To see this set the variance of all shocks equal to zero except for the predominant one and then use $\langle 9\rangle$ and $\langle 16\rangle$ to show that $\sigma_{F 4 x}^{2}=0$. This is clcar upon inspection when domestic monetary shocks or foreign price shocks are predominant in which cases $\gamma=1$ and $\gamma=0$.

21. The derivation of this expression uses the definitions of the $a$ 's and $b$ 's that were given earlier. Proof of this result, as well as of similar results for the other two cases, is available from the author upon request.

22. The figure is drawn for a given value of $\sigma_{m}^{2}$. Increases in $\sigma_{m}^{2}$ raise the value of $\sigma_{F k x}^{2}$ for any given value of $\sigma_{*}^{2}$ (i.e. they shift the $\sigma_{F l e x}^{2}$ schedule upward); the $\sigma_{F l e x}^{2}$ schedule becomes identical to the $\sigma_{F i x}^{2}$ schedule as $\sigma_{m \rightarrow \infty}^{2} \rightarrow$. The asymptote for $\sigma_{F l e x}^{2}$ shown in Figure 1 can be found by evaluating $\gamma$ at $\sigma_{m}^{2}=\infty$ and using the resulting expression in $\langle 16\rangle$.

23. I have not been able to generalize this result to cases where there is more than one real shock accompanying shocks to the domestic money supply. The difficulty arises because the adjustment mechanism, and hence the stochastic structure of the economy, is different under the two regimes. For this reason, it may be impossible to demonstrate the general superiority of one regime over the other.

24. Of course the more disciplined monetary policy is the better a system of flexible exchange rates will perform. This is illustrated by the fact that reductions in $\sigma_{m}^{2}$ shift the $\sigma_{F k x}^{2}$ schedule downward in Figure 1.

25. These policy-ineffectiveness results do not depend on agents observing the exchange rate. In fact, when agents have differential information monetary policy under flexible exchange rates may be effective precisely because agents observe the exchange rate. See Kimbrough (1982). 


\section{References}

Barro, R.J., 'Rational Expectations and the Role of Monetary Policy', J. Monetary Econ., January 1976, 2: $1-32$.

Boyer, R.S., 'Optimal Foreign Exchange Market Intervention', J. Pol. Econ., December 1978, 86: $1045-1055$.

Canzoneri, M.B., D.W. Henderson and K.S. RogofF, 'The Information Content of the Interest Rate and Optimal Monetary Policy', unpublished manuscript, Board of Governors of the Federal Reserve, 1981.

Chan, K.S., 'Rational Expectations and the Optimal Foreign Exchange Regimes', Can. J. Econ., February 1982, 15: 164-174.

Cox, M.W., 'Unanticipated Money, Output, and Prices in the Small Economy', J. Monetary Econ., July 1980, 6: 359-384.

FLOOD, R.P. AND N.P. MARION, 'The Transmission of Disturbances under Alternative Exchange Rate Regimes with Optimal Indexing', Q.J. Econ., February 1982, 96: 42-66.

Friedman, M., 'The Case for Flexible Exchange Rates', in his Essays in Positive Economics, Chicago: University of Chicago Press, 1953.

Kimbrough, K.P., 'Aggregate lnformation and the Role of Monetary Policy in an Open Economy', unpublished manuscript, Duke University, 1982.

Lucas, R.E., Jr., 'Some International Evidence on Output-Inflation Tradeoffs', Am. Econ. Rev', June 1973, 63: 326-334.

LuCAS, R.E., Jr., 'Econometric Policy Evaluation: A Critique', in Vol. 1 of the Carnegie-Rochester Conference Series on Public Policy, a supplementary series to the J. Monetary Econ, 1976, pp. 19-46.

SAIDI, N.H., 'Fluctuating Exchange Rates and the International Transmission of Economic Disturbances', J. Money, Credit, and Banking, November 1980, 12: 575-591.

SARGENT, T. J. AND N. WALlACE, 'Rational Expectations, the Optimal Monetary Instrument, and the Optimal Money Supply Rule', J. Pol. Econ., April 1975, 83: 241-254.

Weber, W.E., 'Output Variability under Monetary Policy and Exchange Rate Rules', J. Pol. Econ., August 1981, 89: 733-751. 